\title{
An arm with a mind of its own
}
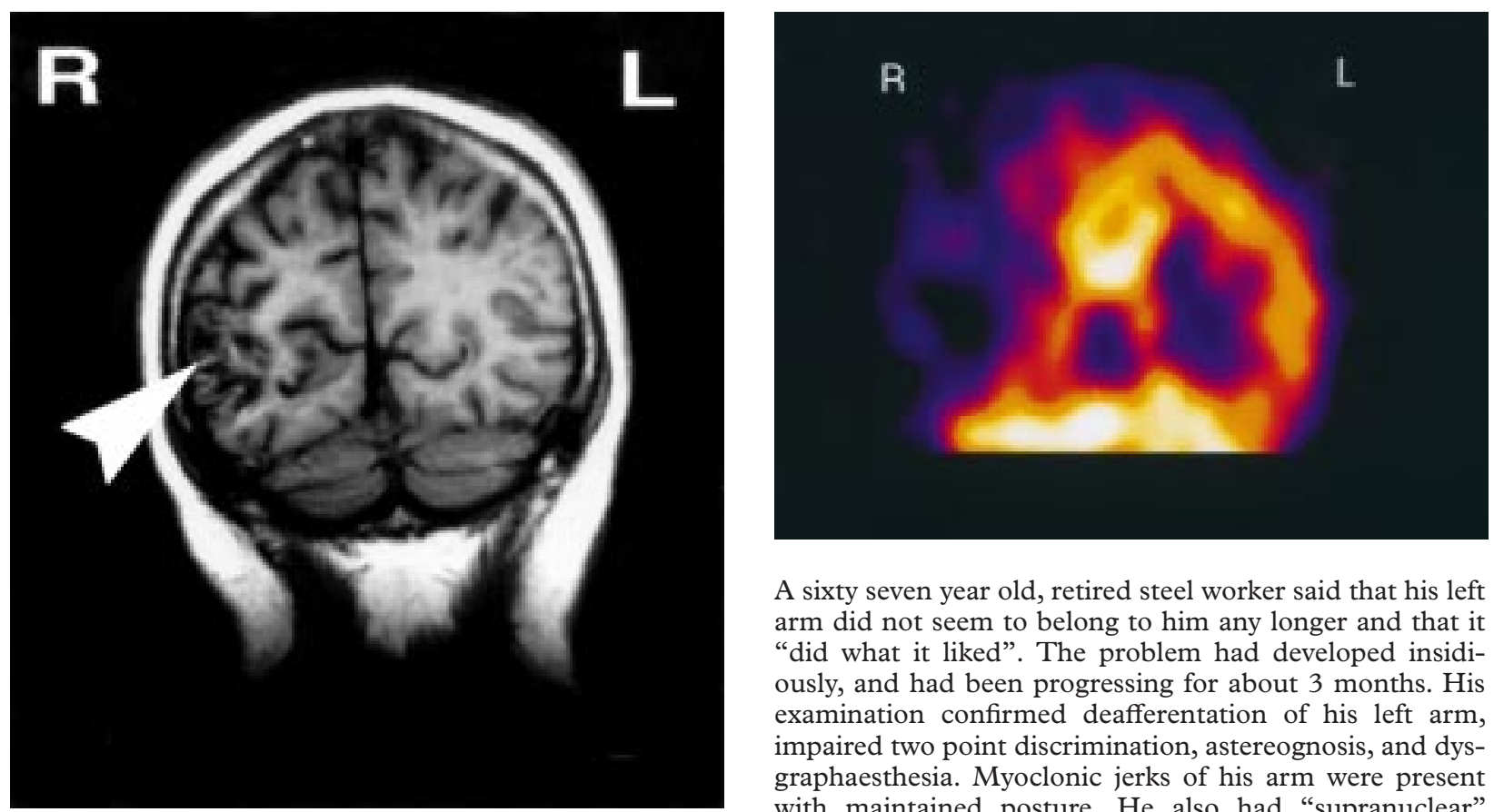

A sixty seven year old, retired steel worker said that his left arm did not seem to belong to him any longer and that it "did what it liked". The problem had developed insidiously, and had been progressing for about 3 months. His examination confirmed deafferentation of his left arm, impaired two point discrimination, astereognosis, and dysgraphaesthesia. Myoclonic jerks of his arm were present with maintained posture. $\mathrm{He}$ also had "supranuclear" restriction of upgaze, diffuse paratonic limb rigidity, and wide based gait. Psychometry disclosed diffuse cerebral dysfunction, not simply restricted to the right parietal lobe. Magnetic resonance imaging of the head showed diffuse atrophy and ventriculomegaly, but also an area of localised cortical atrophy in the right parieto-occipital region mostly affecting the grey matter and not involving the basal ganglia (figure top left, arrow).

${ }^{99}$ Techentium-hexamethylproyleneamineoxime-SPECT confirmed a large area of absent perfusion in this area (figure top right). Somatosensory evoked potentials from stimulation of the left median nerve failed to produce a clear contralateral parietal response (figure bottom 1), compared with the normal side (figure bottom 2). The clinical, radiological, and electrophysiological features of this case were consistent with a diagnosis of corticobasal ganglionic degeneration.

We are grateful to Drs E Teasdale and A I Weir for interpreting the radiological and evoked potential studies, and Drs R Petty and D Grosset for their permission to report these findings on this patient.

H T S BENAMER

Neurology Department, Institute of Neurological Sciences, 1345 Govan Road, Glasgow G51 4TF, UK

R DE SILVA

Neurology Department, Essex Centre for Neurological Sciences, Oldchurch Hospital, Oldchurch Road, Romford, Essex RM 7 OBE, UK

Correspondence to: Dr H T S Benamer, Neurology Department, Institute of Neurological Sciences, 1345 Govan Road, Glasgow G51 4TF, UK. 